\title{
Echocardiographic assessment and N-terminal pro-brain natriuretic peptide in hypertensives with metabolic syndrome
}

\author{
Paweł Krzesińnki ${ }^{1, \text { A-F }}$, Beata Uziebło-Życzkowska, A-F, Grzegorz Gielerak ${ }^{1, A, C-F}$, Adam Stańczyk ${ }^{1, A, C-F}$, \\ Katarzyna Piotrowicz ${ }^{1}, A, C-F$, Wiesław Piechota, ${ }^{2, B-F}$, Paweł Smurzyński ${ }^{1}, B, C, E, F$, Andrzej Skrobowski1, B, E,F \\ ${ }^{1}$ Department of Cardiology and Internal Diseases, Military Institute of Medicine, Warszawa, Poland \\ ${ }^{2}$ Department of Laboratory Diagnostics, Military Institute of Medicine, Warszawa, Poland \\ A - research concept and design; $\mathrm{B}$ - collection and/or assembly of data; $\mathrm{C}$ - data analysis and interpretation; \\ $D$ - writing the article; $E$ - critical revision of the article; $F$ - final approval of article
}

\section{Address for correspondence \\ Paweł Krzesiński}

E-mail:pkrzesinski@wim.mil.pl

\section{Funding sources}

The study was supported by the Military Institute of Medicine, Warszawa, Poland (statutionary grant No. 69/WIM).

Conflict of interest

none declared

Received on August 26, 2014

Revised on November 5, 2014

Accepted on November 7, 2014
DOI

10.17219/acem/33554

\section{Copyright}

Copyright by Author(s)

This is an article distributed under the terms of the

Creative Commons Attribution Non-Commercial License

(http://creativecommons.org/licenses/by-nc-nd/4.0/)

\begin{abstract}
Background. N-terminal pro-brain natriuretic peptide (NT-proBNP) release is associated with left ventricular expansion and pressure overload. Elevation of serum levels of natriuretic peptides is observed in patients with impaired as well as preserved left ventricular systolic function. High NT-proBNP has been shown to be related not only to preload but also to increased afterload, especially blood pressure and arterial stiffness.
\end{abstract}

Objectives. The aim of the study was to evaluate the association of NT-proBNP and echocardiographic parameters in hypertensives with metabolic syndrome.

Material and methods. The study group comprised 133 patients (99 men; mean age $45.9 \pm 9.4$ years) with at least a 3-month history of arterial hypertension (stages 1 and 2) and fulfilling the diagnostic criteria for metabolic syndrome. Following initial clinical assessment, which included NT-proBNP levels, they underwent two-dimensional echocardiography.

Results. Echocardiographic abnormalities were observed in 60 subjects (45.1\%), including left ventricular diastolic dysfunction (LVDdf) in 41 (30.8\%) and left ventricular hypertrophy (LVH) in 35 (26.3\%). Higher NT-proBNP concentrations were observed in patients with LVH, especially in the presence of LVDdf. Further analysis demonstrated that NT-proBNP correlated negatively with septal $E^{\prime}(r=-0.38 ; p=0.015)$ and heart rate $(r=-0.42 ; p=0.006)$ in patients with LVDdf, and positively with left ventricular end diastolic diameter $(r=0.46 ; p=0.006)$ and left ventricular mass index $(r=0.49 ; p=0.005)$ in subjects with LVH. However, the analysis of ROC curves revealed no NT-proBNP level of good sensitivity and specificity in diagnosing LVDdf/LVH (maximal area under the curve 0.571).

Conclusions. Even a relatively low NT-proBNP concentration can be a useful marker of left ventricular hypertrophy and end-diastolic wall stretch. However, in the present study there was no NT-proBNP level of satisfactory predictive value to diagnose LV abnormalities.

Key words: natriuretic peptides, echocardiography, left ventricular hypertrophy, left ventricular diastolic dysfunction 
$\mathrm{N}$-terminal pro-brain natriuretic peptide (NT-proBNP) is the amino terminal fragment of brain natriuretic peptide that is released from the heart in response to ventricular expansion and pressure overload. ${ }^{1,2}$ Elevation of serum levels of natriuretic peptides is observed in patients with impaired as well as preserved left ventricular systolic function, especially those with heart failure., ${ }^{3,4}$ However, high NT-proBNP has been shown to be related not only to preload but also to increased afterload, especially high blood pressure and arterial stiffness. ${ }^{5}$ In patients with arterial hypertension NT-proBNP has been found to be a marker of impaired diastolic function and left ventricular hypertrophy (LVH) ${ }^{5,6}$ Most studies have focused on the relation between natriuretic peptides and echocardiographic measurements, especially left ventricular mass index (LVMI) and markers of left ventricular diastolic dysfunction (LVDdf) derived from mitral flow analysis and tissue Doppler imaging. ${ }^{6,7,8}$ Such observations have also been confirmed by magnetic resonance imaging. ${ }^{9,10}$ NT-proBNP has also been identified as cardiovascular risk factor. ${ }^{11,12}$ However, most of these studies included non-homogenous groups of patients in which co-morbidities could have influenced NT-proBNP assessment.

The aim of the analysis presented in this paper was therefore to evaluate the association of NT-proBNP levels and echocardiographic parameters in patients with essential arterial hypertension and metabolic syndrome.

\section{Material and methods}

The study included 133 patients (99 men; mean age $45.9 \pm 9.4$ years) with at least a 3-month history of arterial hypertension (stages 1 and 2), defined according to the current guidelines. ${ }^{13}$ Exclusion criteria were: (1) confirmed secondary arterial hypertension, (2) improperly controlled arterial hypertension with 3 or more medicines, (3) heart failure, (4) cardiomyopathy, (5) significant heart rhythm disorders, (6) significant valvular heart disease, (7) chronic kidney disease, (8) chronic obstructive pulmonary disease, (9) diabetes, (10) polyneuropathy, (11) peripheral vascular diseases, (12) age $<18$ years or $>65$ years.

All the subjects fulfilled the International Diabetes Federation (IDF) diagnostic criteria for metabolic syndrome, and were recruited from 2 clinical studies performed in the Department of Cardiology and Internal Diseases of the Military Institute of Medicine (Warszawa, Poland) from March 2008 to May 2012. ${ }^{14}$ Both studies were conducted according to the Good Clinical Practice guidelines and the Declaration of Helsinki, and had the approval of the local ethics committee (nos. 3/WIM/2008 and 44/WIM/2010). Each patient provided written informed consent to participate in the study. The demographic and clinical characteristics of the study group are shown in Table 1.
Table 1. Basic clinical characteristics

\begin{tabular}{|c|c|}
\hline Parameters & Study group $(n=133)$ \\
\hline \multicolumn{2}{|c|}{ Clinical parameters } \\
\hline Age [years], mean $\pm S D$ & $45.9 \pm 9.4$ \\
\hline BMI $\left[\mathrm{kg} / \mathrm{m}^{2}\right]$, mean $\pm \mathrm{SD}$ & $32.2 \pm 4.1$ \\
\hline Male, n [\%] & $99(74.4)$ \\
\hline $\mathrm{SBP}[\mathrm{mm} \mathrm{Hg}]$, mean $\pm \mathrm{SD}$ & $143.4 \pm 16.0$ \\
\hline $\mathrm{DBP}[\mathrm{mm} \mathrm{Hg}]$, mean $\pm \mathrm{SD}$ & $91.2 \pm 10.1$ \\
\hline $\mathrm{HR}[\mathrm{bpm}]$, mean $\pm \mathrm{SD}$ & $71.7 \pm 10.1$ \\
\hline Family history of AH, n [\%] & $79(59.8)$ \\
\hline Controlled AH, n [\%] & $21(15.8)$ \\
\hline Treated AH, n [\%] & $68(51.1)$ \\
\hline ACEI, n [\%] & $39(29.3)$ \\
\hline $\mathrm{BB}, \mathrm{n}[\%]$ & $30(22.6)$ \\
\hline$C B, n[\%]$ & $23(17.3)$ \\
\hline Diuretics, n [\%] & $42(31.6)$ \\
\hline $\mathrm{ARB}, \mathrm{n}[\%]$ & $20(15.0)$ \\
\hline Treated dyslipidemia, n [\%] & $71(53.4)$ \\
\hline \multicolumn{2}{|c|}{ Echocardiography } \\
\hline LVEDD $[\mathrm{mm}]$, mean $\pm \mathrm{SD}$ & $50.1 \pm 3.8$ \\
\hline$L A$ dimension $[\mathrm{mm}]$, mean $\pm \mathrm{SD}$ & $38.4 \pm 4.5$ \\
\hline LVMI $\left[\mathrm{g} / \mathrm{m}^{2}\right]$, mean $\pm \mathrm{SD}$ & $96.5 \pm 22.0$ \\
\hline IVRT [ms], mean $\pm \mathrm{SD}$ & $92.0 \pm 13.7$ \\
\hline$E / A$, mean $\pm S D$ & $1.12 \pm 0.28$ \\
\hline $\mathrm{DT}[\mathrm{ms}]$, mean $\pm \mathrm{SD}$ & $184.4 \pm 37.7$ \\
\hline Septal E', mean $\pm S D$ & $8.70 \pm 2.27$ \\
\hline $\mathrm{E} / \mathrm{E}^{\prime}$ ratio, mean $\pm \mathrm{SD}$ & $8.84 \pm 2.32$ \\
\hline LV enlargement, n [\%] & $2(1.5)$ \\
\hline LA enlargement, $n$ [\%] & $44(33.3)$ \\
\hline LVDdf, n [\%] & $41(30.8)$ \\
\hline LVH, n [\%] & $35(26.3)$ \\
\hline \multicolumn{2}{|c|}{ Laboratory tests } \\
\hline Creatinine $[\mathrm{mg} / \mathrm{dL}]$, mean $\pm \mathrm{SD}$ & $0.848 \pm 0.150$ \\
\hline $\mathrm{eGFR}\left[\mathrm{mL} / \mathrm{min} / 1.73 \mathrm{~m}^{2}\right]$, mean $\pm \mathrm{SD}$ & $99.1 \pm 16.5$ \\
\hline $\mathrm{FG}[\mathrm{mg} / \mathrm{dL}]$, mean $\pm \mathrm{SD}$ & $102.8 \pm 13.1$ \\
\hline $\mathrm{T}-\mathrm{C}[\mathrm{mg} / \mathrm{dL}]$, mean $\pm \mathrm{SD}$ & $221.2 \pm 47.5$ \\
\hline $\mathrm{LDL}-\mathrm{C}[\mathrm{mg} / \mathrm{dL}]$, mean $\pm \mathrm{SD}$ & $131.9 \pm 39.2$ \\
\hline $\mathrm{HDL}-\mathrm{C}[\mathrm{mg} / \mathrm{dL}]$, mean $\pm \mathrm{SD}$ & $47.3 \pm 14.0$ \\
\hline $\mathrm{TG}[\mathrm{mg} / \mathrm{dL}]$, mean $\pm \mathrm{SD}$ & $215.9 \pm 116.0$ \\
\hline NT-proBNP [pg/mL], mean \pm SD & $34.5 \pm 26.6$ \\
\hline
\end{tabular}

A - mitral valve inflow phase A velocity; ACEI - angiotensin converting enzyme inhibitor; $A H$ - arterial hypertension; $A R B$ - angiotensin receptor blocker; BB - beta-blocker; BMI - body mass index; CB - calcium blocker; DBP - diastolic blood pressure; DT - deceleration time; E - mitral valve inflow phase E velocity; eGFR - estimated glomerular filtration rate; FG - fasting glucose; HDL-C - high density lipoproteins; HR - heart rate; IVRT - isovolumetric diastolic time; LA - left atrium; LDL-C - low density lipoproteins; LV - left ventricle; LVDdf - left ventricular diastolic dysfunction; LVEDD - left ventricular end diastolic diameter; LVH - left ventricular hypertrophy; NT-proBNP - N-terminal pro-brain natriuretic peptide; SBP - systolic blood pressure; septal $E^{\prime}$ - septal annulus early diastolic velocity; T-C - total cholesterol; TG - triglycerides. 
Clinical examinations were performed with particular consideration for any family history of arterial hypertension, cardiovascular risk factors and symptoms indicating a secondary cause of arterial hypertension. Office blood pressure measurement (Omron M4 Plus, Kyoto, Japan) was carried out by a technique compliant with the European Society of Cardiology guidelines. ${ }^{13}$ Laboratory tests included evaluation of renal function (creatinine, glomerular filtration rate) and metabolic disturbances.

Two-dimensional echocardiography was performed using standard parasternal, apical, and subcostal views (2.5 MHz transducer VIVID 6E GE Medical System, Wauwatosa, USA). The dimension of the left atrium (LA), left ventricular end diastolic diameter (LVEDD) and interventricular septum diameter (IVSD) were measured in the parasternal long-axis view. The left ventricular ejection fraction was calculated according to Simpson's formula, employing a two-dimensional image of the LV chamber during the systole and diastole in the 4- and 2-chamber apical views.

LVH was diagnosed according to the formula recommended by the American Society of Echocardiography (ASE) for estimating LV mass from 2D linear LV measurements and indexed to body surface area (the cut-off values were LVMI > $115 \mathrm{~g} / \mathrm{m}^{2}$ for men and $>95 \mathrm{~g} / \mathrm{m}^{2}$ for women). ${ }^{15}$

Mitral valve inflow was recorded in the apical 4-chamber view with the pulsed-wave Doppler gate positioned in the LV at the level of the mitral valve edges. The E/A ratio and phase E deceleration time were measured. The apical 5-chamber view allowed simultaneous registration of the flow pattern through the aortic and mitral valves and isovolumic diastolic time calculation. Tissue Doppler imaging was performed in the apical views to obtain mitral annular velocity. The sample volume was positioned at or within $1 \mathrm{~cm}$ of the septal insertion sites of the mitral leaflets and adjusted as necessary (usually 5-10 $\mathrm{mm}$ ) to cover the longitudinal excursion of the mitral annulus during diastole. Additionally, mitral septal annulus early diastolic velocity (septal E') was measured and the E/E' ratio was calculated. A diagnosis of LVDdf was based on current guidelines. ${ }^{15,16}$ The following values were considered abnormal: left atrium $>40 \mathrm{~mm}$ for men and $>38 \mathrm{~mm}$ for women, $\mathrm{E} / \mathrm{A}<0.8$, deceleration time $>200 \mathrm{~ms}$, isovolumic diastolic time $\geq 100 \mathrm{~ms}$, septal $\mathrm{E}^{\prime}<8 \mathrm{~cm} / \mathrm{s}$, E/E' ratio $>8$.

Laboratory tests included fasting glucose, total cholesterol (T-C), low density lipoprotein cholesterol (LDL-C), high density lipoprotein cholesterol (HDL-C), triglycerides, creatinine, estimated glomerular filtration rate (eGFR, calculated using the MDRD equation) and NT-proBNP, estimated using the Elecsys ${ }^{\circledR}$ proBNP Assay (Roche Diagnostics, Hague Rd., Indianapolis, USA). Only patients with NT-proBNP below $125 \mathrm{pg} / \mathrm{mL}$ were included in the statistical analysis.

The statistical analysis was performed using STATISTICA 7.0 software (StatSoft Inc., Tulsa, USA). The dis- tribution and normality of data were assessed by visual inspection and using the Shapiro-Wilk test. Continuous variables were presented as means \pm standard deviations (SD); categorical variables were presented as absolute and relative frequencies (percentages). To analyze differences between subgroups, the analysis of variance (ANOVA) was used for normally distributed variables and the Kruskal-Wallis test when the data were not normally distributed. Detailed inter-subgroup comparisons were performed using the appropriate post-hoc tests. For categorical variables, the $X^{2}$ test and Fisher exact test were used. The assessment of the relations between NT-proBNP and other parameters was performed using the Spearman correlation coefficient. A p-value of $<0.05$ was taken to indicate statistical significance.

\section{Results}

The basic characteristics of the study group are presented in Table 1. Echocardiographic abnormalities were observed in 60 subjects (45.1\%), including LVDdf in 41 cases $(30.8 \%$, all presenting with impaired relaxation, no pseudonormal or restrictive filling pattern observed), and LVH in 35 cases (26.3\%). Left atrium enlargement was observed in 44 subjects (33.3\%), and abnormal left ventricular end diastolic diameter in only 2 (1.5\%). No significant abnormalities in LV wall contractility, left ventricular ejection fraction or heart valves were observed.

A comparative analysis was performed for 4 subgroups selected on the basis of the presence of LVDdf and/or LVH: Subgroup A consisted of patients without either LVDdf or LVH; subgroup B comprised cases with LVDdf but without LVH; Subgroup C was made up of patients without LVDdf but with LVH; while subgroup D had both LVDdf and LVH. Significant differences between the subgroups were observed for NT-proBNP ( $p<0.05)$, higher concentrations of which were observed in the patients with LVH, especially in the presence of LVDdf (subgroup D) - see Fig. 1.

The patients with echocardiographic abnormalities were older and were characterized by higher systolic and diastolic blood pressure. Subgroup B had a higher heart rate, especially in comparison with subgroup C. Left atrium enlargement and higher left ventricular end diastolic diameter were related to $\mathrm{LVH}$, especially in tandem with LVDdf (subgroup D). Only incidental differences were observed for the other parameters assessed (Table 2).

Further analysis demonstrated that NT-proBNP correlated negatively with septal $E^{\prime}(r=-0.38 ; p=0.015)$ and heart rate $(r=-0.42 ; \mathrm{p}=0.006)$ in patients with LVDdf, and positively with left ventricular end diastolic diameter $(\mathrm{r}=0.46 ; \mathrm{p}=0.006)$ and LVMI $(\mathrm{r}=0.49 ; \mathrm{p}=0.005)$ in subjects with LVH. No significant correlation with other parameters was found (Table 3, Fig. 2). 
Table 2. Comparison between subgroups selected on the base of presence of LVDdf and/or LVH

\begin{tabular}{|c|c|c|c|c|c|c|}
\hline \multirow[b]{2}{*}{ Parameters } & \multicolumn{4}{|c|}{ Subgroups } & \multicolumn{2}{|c|}{$\mathrm{p}$-values } \\
\hline & $\begin{array}{c}A \\
n=73\end{array}$ & $\begin{array}{c}B \\
n=25\end{array}$ & $\begin{array}{c}C \\
n=19\end{array}$ & $\begin{array}{c}D \\
n=16\end{array}$ & $\begin{array}{c}\text { ANOVA/ } \\
\text { Kruskal-Wallis/ } \\
\text { X²/Fisher tests }^{2}\end{array}$ & post-hoc tests \\
\hline \multicolumn{7}{|c|}{ Clinical parameters } \\
\hline Age [years], mean $\pm S D$ & $43.4 \pm 9.8$ & $46.6 \pm 8.2$ & $49.2 \pm 8.3$ & $52.2 \pm 6.1$ & $<0.05$ & $A \vee s D^{*}$ \\
\hline $\mathrm{BMI}\left[\mathrm{kg} / \mathrm{m}^{2}\right]$, mean $\pm \mathrm{SD}$ & $32.1 \pm 3.9$ & $33.3 \pm 4.2$ & $30.9 \pm 4.6$ & $32.3 \pm 3.7$ & ns & \\
\hline Male, n [\%] & $59(80.8)$ & $19(76.0)$ & $11(57.9)$ & $10(63.5)$ & $<0.05$ & $A \vee s C^{*}$ \\
\hline $\mathrm{SBP}[\mathrm{mm} \mathrm{Hg}]$, mean $\pm \mathrm{SD}$ & $139.0 \pm 14.9$ & $147.5 \pm 13.9$ & $145.1 \pm 16.2$ & $154.7 \pm 17.0$ & $<0.05$ & $A$ vs $D^{*}$ \\
\hline $\mathrm{DBP}[\mathrm{mm} \mathrm{Hg}]$, mean $\pm \mathrm{SD}$ & $89.6 \pm 9.3$ & $93.9 \pm 11.0$ & $89.5 \pm 11.3$ & $96.3 \pm 8.9$ & $<0.05$ & $\begin{array}{l}A \vee s B^{*} \\
A \vee s D^{*}\end{array}$ \\
\hline $\mathrm{HR}[\mathrm{bpm}]$, mean $\pm \mathrm{SD}$ & $71.7 \pm 9.3$ & $76.6 \pm 10.2$ & $64.8 \pm 10.3$ & $72.4 \pm 9.1$ & $<0.05$ & $\begin{array}{l}A \vee s C^{*} \\
B \vee s C^{* *}\end{array}$ \\
\hline Family history of $\mathrm{AH}, \mathrm{n}$ [\%] & $44(60.3)$ & $16(64.0)$ & $11(57.9)$ & $8(50.0)$ & ns & \\
\hline Controlled AH, n [\%] & $13(17.8)$ & $3(12.0)$ & $3(15.8)$ & $2(12.5)$ & ns & \\
\hline Untreated AH, n [\%] & $31(42.5)$ & $11(44.0)$ & $13(68.4)$ & $10(62.5)$ & $<0.05$ & $A$ vs $C^{*}$ \\
\hline Treated AH, n [\%] & $42(57.5)$ & $14(56.0)$ & $6(31.6)$ & $6(37.5)$ & $<0.05$ & $A \vee s C^{*}$ \\
\hline$A C E I, n[\%]$ & $26(35.6)$ & $4(16.0)$ & $3(15.8)$ & $6(37.5)$ & ns & \\
\hline $\mathrm{BB}, \mathrm{n}[\%]$ & $16(21.9)$ & $7(28.0)$ & $4(21.1)$ & $3(18.8)$ & ns & \\
\hline$C B, n[\%]$ & $13(17.8)$ & $5(20.0)$ & $3(15.8)$ & $2(12.5)$ & ns & \\
\hline Diuretics, n [\%] & $27(37.0)$ & $8(40.0)$ & $2(10.5)$ & $5(31.3)$ & $<0.05$ & $A$ vs $C^{*}$ \\
\hline $\mathrm{ARB}, \mathrm{n}[\%]$ & $11(15.1)$ & $7(28.0)$ & $2(10.5)$ & $0(0.0)$ & $<0.05$ & $B v s D^{*}$ \\
\hline \multicolumn{7}{|c|}{ Echocardiography } \\
\hline LVEDD $[\mathrm{mm}]$, mean $\pm \mathrm{SD}$ & $49.7 \pm 3.6$ & $49.5 \pm 3.4$ & $50.9 \pm 4.3$ & $51.9 \pm 4.2$ & $<0.05$ & $\begin{array}{l}A v s D^{*} \\
B \vee s D^{*}\end{array}$ \\
\hline LA dimension [mm], mean \pm SD & $38.3 \pm 2.6$ & $38.5 \pm 3.4$ & $39.1 \pm 3.5$ & $37.7 \pm 9.8$ & ns & \\
\hline LV enlargement, n [\%] & $0(0.0)$ & $0(0.0)$ & $1(5.3)$ & $1(6.25)$ & $<0.05$ & $\begin{array}{l}A \text { vs } C^{*} \\
A \text { vs } D^{*}\end{array}$ \\
\hline LA enlargement, n [\%] & $19(26.0)$ & $8(32.0)$ & $9(47.4)$ & $8(50.0)$ & $<0.05$ & $\begin{array}{l}A \vee s C^{*} \\
A \vee s D^{*}\end{array}$ \\
\hline \multicolumn{7}{|c|}{ Laboratory tests } \\
\hline Creatinine $[\mathrm{mg} / \mathrm{dL}]$, mean $\pm \mathrm{SD}$ & $0.867 \pm 0.159$ & $0.824 \pm 0.133$ & $0.839 \pm 0.138$ & $0.806 \pm 0.139$ & ns & \\
\hline $\mathrm{eGFR}\left[\mathrm{mL} / \mathrm{min} / 1.73 \mathrm{~m}^{2}\right]$ mean $\pm \mathrm{SD}$ & $99.9 \pm 17.8$ & $100.6 \pm 15.4$ & $94.7 \pm 12.2$ & $98.2 \pm 16.4$ & ns & \\
\hline
\end{tabular}

${ }^{*} \mathrm{p}<0.05 ;{ }^{* *} \mathrm{p}<0.01$; A - mitral valve inflow phase A velocity; ACEI - angiotensin converting enzyme inhibitor; AH - arterial hypertension; ARB - angiotensin receptor blocker; BB - beta-blocker; BMI - body mass index; CB - calcium blocker; DBP - diastolic blood pressure; DT - deceleration time; E - mitral valve inflow phase E velocity, eGFR - estimated glomerular filtration rate; HR - heart rate; IVRT - isovolumetric diastolic time; LA - left atrium; LV - left ventricle; LVDdf - left ventricular diastolic dysfunction; LVEDD - left ventricular end diastolic diameter; LVH - left ventricular hypertrophy; SBP - systolic blood pressure; septal $E^{\prime}$ - septal annulus early diastolic velocity.

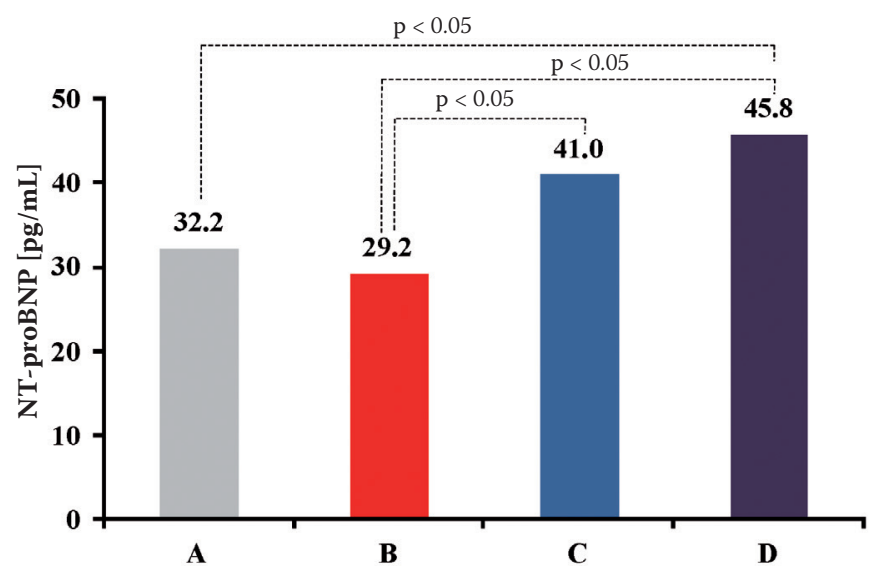

To evaluate the discriminative power of NT-proBNP as a classifier of echocardiographic abnormalities (LVH and/ or LVDdf), the receiver operating characteristic (ROC) was calculated. An analysis of the curves (Fig. 4) revealed that no NT-proBNP level combined both good sensitivity and good specificity (maximal area under the curve: 0.571). The NT-proBNP level with $80 \%$ sensitivity was $15.5 \mathrm{pg} / \mathrm{mL}$ (with $34.2 \%$ specificity), and the level with $80 \%$ specificity was $58.8 \mathrm{pg} / \mathrm{mL}$ (with $21.7 \%$ sensitivity).
Fig. 1. Comparison of NT-proBNP concentration between subgroups selected on the basis of the presence of LVDdf and/or LVH 
Table 3. Correlations between NT-proBNP and other parameters in patients with LVDdf (left column) and LVH (right column)

\begin{tabular}{|c|c|c|c|c|c|}
\hline \multicolumn{3}{|c|}{ LVDdf $(n=41)$} & \multicolumn{3}{|c|}{$\mathrm{LVH}(\mathrm{n}=35)$} \\
\hline \multicolumn{6}{|c|}{ NT-proBNP versus } \\
\hline Parameters & $\mathrm{R}$ & $p$-value & Parameters & $\mathrm{R}$ & $p$-value \\
\hline Age & 0.27 & 0.086 & age & -0.23 & 0.175 \\
\hline SBP & -0.01 & 0.943 & SBP & 0.17 & 0.335 \\
\hline DBP & 0.13 & 0.420 & DBP & 0.09 & 0.596 \\
\hline$H R$ & -0.42 & 0.006 & $H R$ & 0.08 & 0.642 \\
\hline BMI & 0.06 & 0.732 & BMI & 0.12 & 0.493 \\
\hline Creatinine & -0.19 & 0.241 & creatinine & -0.18 & 0.298 \\
\hline eGFR & 0.06 & 0.708 & eGFR & 0.33 & 0.055 \\
\hline IVSDD & 0.19 & 0.229 & IVSDD & 0.26 & 0.129 \\
\hline LVEDD & 0.14 & 0.400 & LVEDD & 0.46 & 0.006 \\
\hline LA dimension & 0.21 & 0.204 & LA dimension & 0.24 & 0.170 \\
\hline LVMI & 0.23 & 0.165 & LVMI & 0.49 & 0.005 \\
\hline LVEF & -0.09 & 0.588 & LVEF & -0.19 & 0.289 \\
\hline IVRT & 0.25 & 0.113 & IVRT & -0.08 & 0.633 \\
\hline$E / A$ & -0.29 & 0.070 & $E / A$ & -0.02 & 0.905 \\
\hline DT & 0.16 & 0.316 & DT & 0.01 & 0.958 \\
\hline Septal E' & -0.38 & 0.015 & septal E' & -0.02 & 0.911 \\
\hline$E / E^{\prime}$ & 0.22 & 0.169 & $E / E^{\prime}$ & 0.06 & 0.753 \\
\hline
\end{tabular}

A - mitral valve inflow phase A velocity; BMI - body mass index; DBP - diastolic blood pressure; DT - deceleration time; $\mathrm{E}$ - mitral valve inflow phase E velocity, eGFR - estimated glomerular filtration rate; HR - heart rate; IVRT - isovolumetric diastolic time; LA - left atrium; LV - left ventricle; LVEDD - left ventricular end diastolic diameter; NT-proBNP - N-terminal pro-brain natriuretic peptide; SBP - systolic blood pressure; septal E' - septal annulus early diastolic velocity.

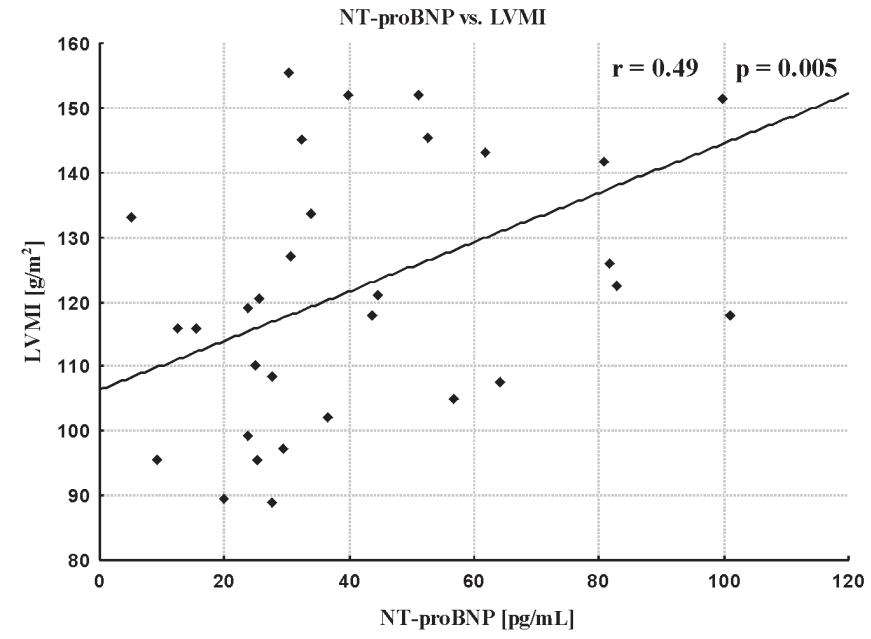

Fig. 2a. Correlations of NT-proBNP with LVMI in patients with LVH

\section{Discussion}

The results of the present study confirmed significant differences between patients with and without LVH and/ or LVDdf. The inter-group differences in age, blood pressure and echocardiographic abnormalities are well known and do not require additional comments. Thus, addressing the aim of the study, the discussion focuses on the association of NT-proBNP with hemodynamic and structural echocardiographic parameters.

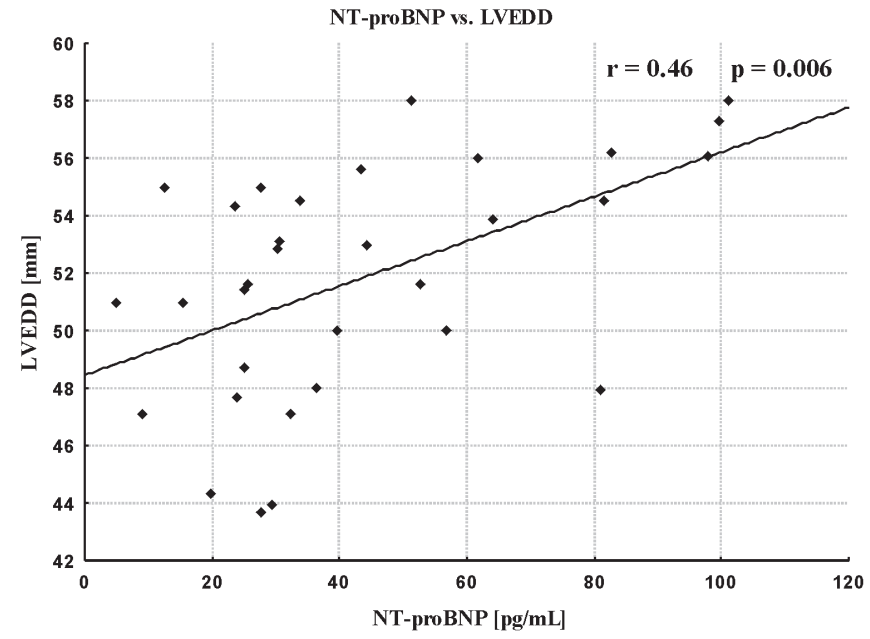

Fig. 2b. Correlations of NT-proBNP with LVEDD in patients with LVH

The analysis revealed that even NT-proBNP values $<125 \mathrm{pg} / \mathrm{mL}$ are clinically important and provide pathophysiological information. The results confirmed the association of NT-proBNP release with both LVH and left ventricular filling pattern. The accuracy of low values of natriuretic peptides for detecting abnormalities in heart morphology and hemodynamics has been confirmed in some studies. Mueller et al. defined the NT-proBNP level of $39 \mathrm{pg} / \mathrm{mL}$ as highly sensitive (90\%) in detecting cardiac structural diseases in echocardiography. ${ }^{17}$ Lubien et al. 


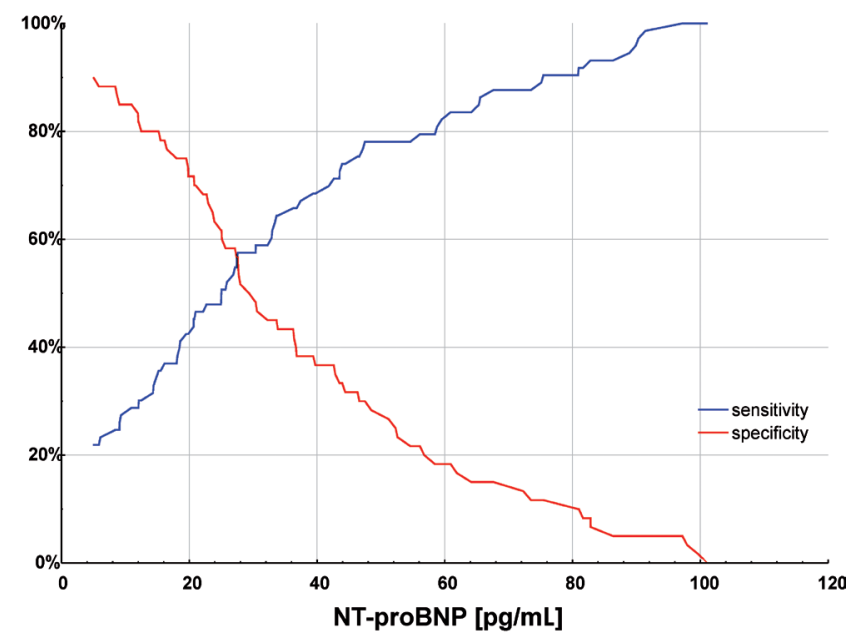

Fig. 3. Sensitivity and specificity curves for NT-proBNP

used a cut-off value of brain natriuretic peptide $62 \mathrm{pg} / \mathrm{mL}$ to indentify patients with LVDdf with $85 \%$ sensitivity and $83 \%$ specificity. ${ }^{7}$ Karaca et al. reported even better accuracy $-80 \%$ sensitivity and $100 \%$ specificity - with a cut-off value of $37 \mathrm{pg} / \mathrm{mL} .{ }^{18}$ Wei et al. noted the high diagnostic value of brain natriuretic peptide $>40 \mathrm{pg} / \mathrm{mL}$ in the assessment of left ventricular end diastolic diameter. ${ }^{19}$ The authors of those studies suggested that low natriuretic peptide levels might be able to rule out clinically significant echocardiographic abnormalities.

\section{NT-ProBNP and left ventricular hypertrophy}

In the present study patients with arterial hypertension and LVH had higher values of NT-proBNP. Moreover, NT-proBNP correlated positively with left ventricular end diastolic diameter. These observations confirm the association of NT-proBNP concentration with prolonged LV overload and myocyte stretch. ${ }^{20}$ These effects are even more apparent in the case of LVH. Goetze et al. confirmed that increased NT-proBNP is independently related to the echocardiographic features of $\mathrm{LVH}$ in the general population (3497 patients). ${ }^{21}$ A correlation between NT-proBNP and LVMI evaluated by magnetic resonance imaging was also shown by Hildebrandt et al. ${ }^{9}$ Moreover, Rivero Otero et al. found that NT-proBNP was elevated in patients with LVH, even in normotensives. ${ }^{22}$ Therefore, NTproBNP, as a biochemical marker of LVMI, ${ }^{23}$ appears to be useful in screening for LVH. ${ }^{4}$ In contrast, some studies have revealed no association between natriuretic peptides and LVH, especially in the early phase of arterial hypertension. ${ }^{24}$ Talwar et al. found that the presence of LVH did not affect NT-proBNP concentrations when LV diastolic function was not impaired. ${ }^{25}$ However, the results of the present study show that even relatively low values of NTproBNP concentration reflect LVMI, supporting its potential role as a marker for LVH.

\section{NT-ProBNP and LVDdf}

There was no significant difference in NT-proBNP between subgroups with and without LVDdf when LVMI was not increased (subgroups A and B). This can be explained by the fact that the study group included patients with mild/moderate arterial hypertension and without any severe hemodynamic dysfunction (no subjects with advanced pseudonormal or restrictive filling pattern). However, further analysis revealed that a higher level of NT-proBNP was related to lower septal annulus early diastolic velocity (septal E'), an indicator of LV filling pressure. The association of NT-proBNP and LVDdf in arterial hypertension has been shown in other studies. Mak et al. observed a significant correlation of brain natriuretic peptide level with $E / E^{\prime}(r=0.48)$, another marker of LVDdf. ${ }^{26}$ Ceyhan et al. found an even more pronounced relationship between NT-proBNP and E/E' $(r=0.80, \mathrm{p}<0.0001)$, but in a small sample group $(n=40){ }^{2}$ Those observations might be explained by defective active relaxation and increased stiffness resulting in elevated left ventricular filling pressures. In those patients, higher NT-proBNP release was probably provoked by LV pressure overload and tension. This kind of neurohormonal response can be an early marker of misbalance in ventricular-vascular interactions. ${ }^{27,28}$

None of the patients in the present study reported symptoms specific for heart failure. However, Lubien et al. found that natriuretic peptide levels rose along with diastolic abnormalities, even before the patient had presented with any clinical symptoms. ${ }^{7}$ It is known that hypertensive patients with abnormal left ventricular filling patterns are often asymptomatic during daily activities, and become "symptomatic" only when experiencing high levels of exercise stress, when LV pressures increase. ${ }^{29}$ Early identification of patients with a higher risk of heart failure seems to be crucial to the prevention of the adverse cardiovascular events.

To sum up, like Bettencourt et al., ${ }^{30}$ the present study found that both LVH and hemodynamic abnormalities are related to higher natriuretic peptide levels. This is not surprising, considering that $\mathrm{LVH}$ is a marker of $\mathrm{LV}$ remodelling in response to increased wall stress, and LVDdf is its hemodynamic consequence. However, the ROC analysis did not indicate any NT-proBNP level as a classifier with both good sensitivity and high specificity, which limits the use of this simple marker to diagnose LV abnormalities.

\section{Limitations}

The authors are aware that the small sample size of the subgroups and the retrospective design are limitations of the study. The low prevalence of LVDdf and LVH could influence the statistical power of the results. Moreover, pharmacotherapy could affect the hemodynamics, heart morphology and laboratory results. Additionally, slight 
incidental differences were observed for other parameters (gender distribution, pharmacotherapy). It is worth emphasizing that the concentration on hypertensives with metabolic syndrome limited the potential influence of obesity distribution on the parameters analyzed. These limitations should not create a significant bias, but the results should be considered carefully as relating to a particular group of patients.

\section{Conclusions}

Echocardiography and NT-proBNP are shown to be complementary methods in the assessment of hemodynamic disturbances in arterial hypertension. Even relatively low NT-proBNP concentrations can be a useful marker of left ventricular hypertrophy and end-diastolic wall stretch. However, in the present study, there was no NT-proBNP level of satisfactory predictive value to diagnose LV abnormalities.

\section{References}

1. McCullough PA, Neyou A. Comprehensive review of the relative clinical utility of B-type natriuretic peptide and $\mathrm{N}$-terminal proB-type natriuretic peptide assays in cardiovascular disease. Open Heart Failure Journal. 2009;2:6-17.

2. Ceyhan C, Unal S, Yenisey C, Tekten T, Ceyhan FB. The role of N-terminal pro-brain natriuretic peptide in the evaluation of left ventricular diastolic dysfunction: Correlation with echocardiographic indexes in hypertensive patients. Int J Cardiovasc Imaging. 2008; 24(3):253-259.

3. McMurray JJ, Adamopoulos S, Anker SD, et al. ESC Guidelines for the diagnosis and treatment of acute and chronic heart failure 2012: The Task Force for the Diagnosis and Treatment of Acute and Chronic Heart Failure 2012 of the European Society of Cardiology. Eur Heart J. 2012;33(14):1787-1847.

4. Vasan RS, Benjamin EJ, Larson MG, et al. Plasma natriuretic peptides for community screening for left ventricular hypertrophy and systolic dysfunction: The Framingham heart study. JAMA. 2002; 288(10):1252-1259.

5. Bricca G, Lantelme P. Natriuretic peptides: Ready for prime-time in hypertension? Arch Cardiovasc Dis. 2011;104(6-7):403-409.

6. Parekh N, Maisel AS. Utility of B-natriuretic peptide in the evaluation of left ventricular diastolic function and diastolic heart failure. Curr Opin Cardiol. 2009;24(2):155-160.

7. Lubien E, DeMaria A, Krishnaswamy P, et al. Utility of B-natriuretic peptide in detecting diastolic dysfunction: Comparison with Doppler velocity recordings. Circulation. 2002;105(5):595-601.

8. Santosa YP, Tjandrawati A, Noormartany, et al. Comparison of pro B-natriureticpeptide in hypertensive patients with and without diastolic dysfunction. Acta Med Indones. 2008;40(1):19-23.

9. Hildebrandt $P$, Boesen $M$, Olsen M, Wachtell K, Groenning B. $\mathrm{N}$-terminal pro brain natriuretic peptide in arterial hypertension: A marker for left ventricular dimensions and prognosis. Eur J Heart Fail. 2004;6(3):313-317.

10. Morillas P, Castillo J, Quiles J, et al. Usefulness of NT-proBNP level for diagnosing left ventricular hypertrophy in hypertensive patients: A cardiac magnetic resonance study. Rev Esp Cardiol. 2008;61(9): 972-975.

11. Pedersen F, Raymond I, Kistorp C, Sandgaard N, Jacobsen P, Hildebrandt $\mathrm{P}$. N-terminal pro-brain natriuretic peptide in arterial hypertension: A valuable prognostic marker of cardiovascular events. J Card Fail. 2005;11:S70-75.
12. Olsen $\mathrm{MH}$, Wachtell $\mathrm{K}$, Tuxen $\mathrm{C}$, et al. $\mathrm{N}$-terminal pro-brain natriuretic peptide predicts cardiovascular events in patients with hypertension and left ventricular hypertrophy: A LIFE study. J Hypertens. 2004;22(8):1597-1604.

13. Mancia G, De Backer G, Dominiczak A, et al. 2007 Guidelines for the management of arterial hypertension: The Task Force for the Management of Arterial Hypertension of the European Society of Hypertension (ESH) and of the European Society of Cardiology (ESC). J Hypertens. 2007;25:1105-87.

14. Alberti KG, Zimmet P, Shaw J, IDF Epidemiology Task Force Consensus Group. The metabolic syndrome: A new worldwide definition. Lancet. 2005;366:1059-1062.

15. Lang RM, Bierig M, Devereux RB, et al. Recommendations for chamber quantification. Eur J Echocardiogr. 2006;7(2):79-108.

16. Nagueh SF, Appleton CP, Gillebert TC, et al. Recommendations for the evaluation of left ventricular diastolic function by echocardiography. Eur J Echocardiogr. 2009;10(2):165-193.

17. Mueller T, Gegenhuber A, Dieplinger B, Poelz W, Haltmayer M: Capability of B-type natriuretic peptide (BNP) and amino-terminal proBNP as indicators of cardiac structural disease in asymptomatic patients with systemic arterial hypertension. Clin Chem. 2005;51(12):2245-2251.

18. Karaca I, Gülcü E, Yavuzkir M, et al. B-type natriuretic peptide level in the diagnosis of asymptomatic diastolic dysfunction. Anadolu Kardiyol Derg. 2007;7(3):262-267.

19. Wei T, Zeng C, Chen L, et al. Bedside tests of B-type natriuretic peptide in the diagnosis of left ventricular diastolic dysfunction in hypertensive patients. Eur J Heart Fail. 2005;7(1):75-79.

20. Dokainish H. Combining tissue Doppler echocardiography and B-type natriuretic peptide in the evaluation of left ventricular filling pressures: Review of the literature and clinical recommendations. Can J Cardiol. 2007;23(12):983-989.

21. Goetze JP, Mogelvang R, Maage L, et al. Plasma pro-B-type natriuretic peptide in the general population: Screening for left ventricular hypertrophy and systolic dysfunction. Eur Heart J. 2006;27(24): 3004-3010.

22. Rivera Otero JM, Taléns-Visconti R, Salvador $A$, et al. Ventricular hypertrophy increases NT-proBNP in subjects with and without hypertension. Int J Cardiol. 2004;96(2):265-271.

23. Luchner A, Burnett JC Jr, Jougasaki M, et al. Evaluation of brain natriuretic peptide as marker of left ventricular dysfunction and hypertrophy in the population. J Hypertens. 2000;18:1121-1128.

24. Belluardo $\mathrm{P}$, Cataliotti $\mathrm{A}$, Bonaiuto $\mathrm{L}$, et al. Lack of activation of molecular forms of the BNP system in human grade 1 hypertension and relationship to cardiac hypertrophy. Am J Physiol Heart Circ Physiol. 2006;291(4):H1529-1535.

25. Talwar S, Siebenhofer A, Williams B, Ng L. Influence of hypertension, left ventricular hypertrophy, and left ventricular systolic dysfunction on plasma N terminal proBNP. Heart. 2000;83(3):278-282.

26. Mak GS, DeMaria A, Clopton P, Maisel AS. Utility of B-natriuretic peptide in the evaluation of left ventricular diastolic function: Comparison with tissue Doppler imaging recordings. Am Heart J. 2004;148(5):895-902.

27. Cheung BMY, Kumana CR. Natriuretic peptides: Relevance in cardiac disease. JAMA. 1998;280:1983-1984.

28. Maeda K, Tsutamoto T, Wada A, Hisanaga T, Kinoshita M. Plasma brain natriuretic peptide as a biochemical marker of high left ventricular end-diastolic pressure in patients with symptomatic left ventricular dysfunction. Am Heart J. 1998;135:825-832.

29. Ambrosi P, Oddoze C, Habib G. Utility of B-natriuretic peptide in detecting diastolic dysfunction: Comparison with Doppler velocity recordings. Circulation. 2002;106(15):e70.

30. Bettencourt P, Ferreira A, Sousa T, et al. Brain natriuretic peptide as a marker of cardiac involvement in hypertension. Int J Cardiol. 1999; 69(2):169-177. 